\title{
Modeling, Simulation of 3D Label Free Nano Amperometric Biosensor for Early Diagnosis of Cancerous Cells with Sustainable Interfacial Coefficients
}

Babu KK*

Gitam University, Vizag, India

\begin{abstract}
I would like to model and simulate 3D label free Nano Amperometric Biosensor for drug delivery and detection of cancerous cells. An Amperometric biosensor is one which has a biological element and a transducer. The analysis to whom the transduction to take place is referred to as analyte. The biological element I use in my work is enzyme, it can be even a living cell, DNA and proteins. Enzyme which I use in my work is Glucose Oxidase (GODx). The analyte primitively used in experimentation is hydrogen peroxide $\left(\mathrm{H}_{2} \mathrm{O}_{2}\right)$ and cancerous blood. The GODx reacts with $\mathrm{H}_{2} \mathrm{O}_{2}$ and releases out oxygen, the amount of oxygen is calibrated in terms of current in milli amperes, so the biological change is calibrated terms of electrical parameter and so it is called amperometric biosensor. But in actual practice, the process is reversible, we inhale oxygen and exhale $\mathrm{CO}_{2}$, but a biosensor releases Oxygen out and inhales the analyte decomposition. This process is called Direct Current Cyclic Voltammetry. A potentiometric biosensor calibrates the analytes in terms of potential or voltage.
\end{abstract}

Keywords: Biosensor; Cancer; Interfacial coefficients; Amperometric biosensor; Glucose oxidase; Transducer

\section{Introduction}

\section{Construction of amperometric biosensor}

A biosensor is one which has outer membrane and Semipermeable membrane, it has 3 electrodes namely working electrode, Reference electrode and counter Electrode the enzyme is applied to working electrode and analyte is kept in the form of bulk solution [1]. The ground surface is referred to substrate. When substrate appears in bulk Solution, the sensor action starts. We apply a fixed potential between counter and reference electrode and vary the potential between working and counter electrode. The variation of potential results in current order of milli amperes [2]. The nano material Carbon Nano tubes can be used as Electrodes, because CNT are hardest materials than graphite and metals. CNTS have good electrical conductivity and ecofriendly to biological applications. Metallic electrodes electrolyze soon before $-0.05 \mathrm{~V}$, and sensor action is not fruitful. CNTS have No problems of such kind.

\section{Development of equations}

Develop equations for outer membrane under ideal conditions and under stress when a replaceable array is attached [3]. Then inner stress on the sensor increases. This may affect the transduction, so the interfacial coefficients should be adjusted in such a way that there is NO change in Biosensor action.

a) Inner stress also gets affected, so there should adjustable inner parameters which should NOT affect the overall sensing.

b) The interfacial coefficients involve De (diffusion of analyte under external conditions) and Di (diffusion under internal conditions), S (Substrate), P (product) and E (Enzyme) (Figure 1).

Following the basic equation of Michaelas Menton:

$$
\mathrm{E}+\mathrm{S} \longrightarrow \mathrm{ESS} \longrightarrow \mathrm{E}+\mathrm{P}
$$

As my sensor is 3 dimensional, consider the basic dimensions $\mathrm{X}, \mathrm{Y}$, and $\mathrm{Z}$ (Figure 2).
The equations governing for the above system are

$$
\left(\frac{d S}{d X}+\frac{d S}{d Y}+\frac{d S}{d Z}\right)+\left(\frac{d E}{d x}+\frac{d E}{d Y}+\frac{d E}{d Z}\right) \rightarrow\left(\frac{d P}{d x}+\frac{\partial P}{\partial Y}+\frac{\partial P}{\partial Z}\right)+\left(\frac{d E}{d x}+\frac{d E}{d Y}+\frac{d E}{d Z}\right)
$$

Equations for electrodes:

As there are 3 electrodes, namely working, counter electrode and reference electrode, the equations are given by following the basic NERST EQUATION:
$\mathrm{I}=\mathrm{N}$.De. F.Q
$\mathrm{I}=$ Current Flow
$\mathrm{N}=\mathrm{No}$ of electrons
$\mathrm{F}=$ Faraday's Constant $=96500$ coloumbs
$\mathrm{Q}=$ Charge developed
De=Diffusion coefficient

Differentiating the above equation WRT time, we get

$\mathrm{Di} / \mathrm{dt}=$ N.De.F dq/dt.

We apply $\mathrm{H}_{2} \mathrm{O}_{2}$ on working electrode and the potential between working and reference electrode is set to $-0.05 \mathrm{~V}$. The enzyme is GLUCOSE OXIDASE $\left(\mathrm{C}_{6} \mathrm{H}_{12} \mathrm{O}_{6}\right)$ is considered in immobilized condition.

*Corresponding author: K Kalyan Babu, Assistant Professor, Gitam University, Rushikonda 530045, Vizag, Andhra Pradesh, India, Tel: 8497917773; E-mail: kalyankillana@gmail.com

Received September 19, 2016; Accepted September 26, 2016; Published September 30, 2016

Citation: Babu KK (2016) Modeling, Simulation of 3D Label Free Nano Amperometric Biosensor for Early Diagnosis of Cancerous Cells with Sustainable Interfacial Coefficients. J Biosens Bioelectron 7: 222. doi: 10.4172/21556210.1000222

Copyright: @ 2016 Babu KK. This is an open-access article distributed under the terms of the Creative Commons Attribution License, which permits unrestricted use, distribution, and reproduction in any medium, provided the original author and source are credited. 


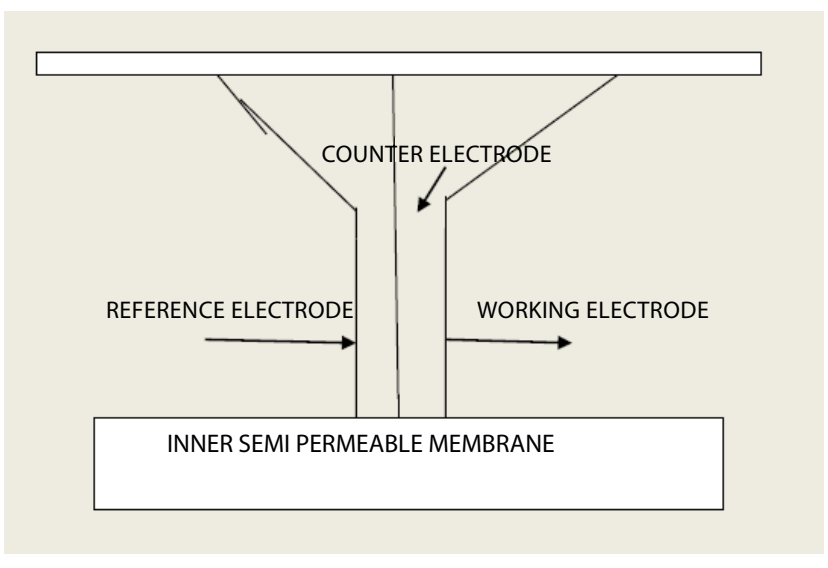

Figure 1: A simple view of amperometric biosensor.

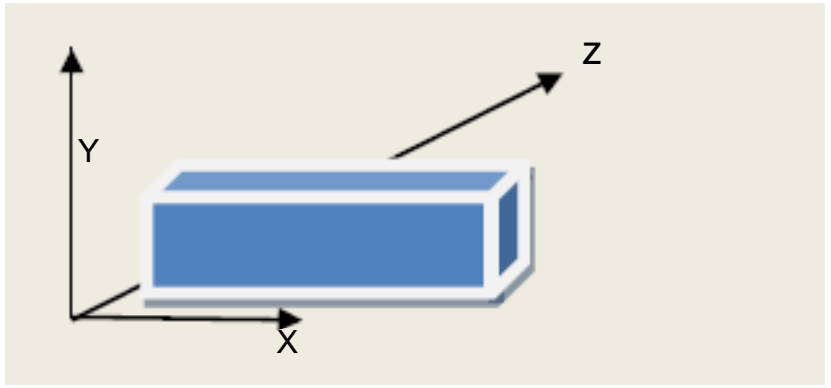

Figure 2: The above diagram shows the 3 Dimensional view of BIOSENSOR.

The reaction is given by:

\section{$\mathrm{C}_{6} \mathrm{H}_{12} \mathrm{O}_{6}+\mathrm{H}_{2} \mathrm{O}_{2} \longrightarrow$ GLUCONIC ACID+OXYGEN}

The biosensor action commences when substrate appears in bulk solution. The oxygen is evolved and is made direct proportional to current in milliamps (Figure 3).

The governing equations for Biosensor actions are: I have considered enzyme under immobilized conditions (QUASI STEADY STATE CONDITION)

$$
D e \cdot \frac{E s s}{S+E} \rightarrow D p \cdot \frac{P}{S b+E s s}
$$

Where,

De=Diffusion coefficient of enzyme

$\mathrm{Dp}=$ Diffusion coefficient of product

Ess=Enzyme under steady state

$\mathrm{Sb}=$ Substrate under bulk solution.

\section{Cancer}

CANCER is a dangerous disease growing all over the world exponentially day by day. Cancer is also known as carcinoma and tumor [4]. Cancer is not transferrable, but it causes a negative mind set for the other persons who live nearer to cancer patient. There are many kinds of cancer namely Brain cancer, lung cancer, stomach cancer, liver cancer, breast cancer, blood cancer leg cancer, thyroid cancer etc. Cancer cells appear as living cells initially, but slowly they lose mass and become light weight and loose contact with skin and perish the patient. Cancer can be eradicated by RF Diathermy, radiation therapy, where UV light is exposed over the cancer cells and destroy them permanently. Cancer is also termed to be carcinoma [5]. Cancer is not hereditary disease; it can be caused to any person at any time. The main causes of cancer in males are because of smoking tobacco, drinking alcohol. Drinking too much of alcohol causes liver cancer either in males or females. Smoking in human beings causes formation of thick mass in lungs which is very dangerous to lungs which finally leads to formation of lung carcinoma. Cervix is females reproductive organ. It leads to release of hormones every time. During intercourse the release of hormones will be more. Having multiple sex partners, leads to cervix cancer, aids. But the cervix cancer can be diagnosed by examining white discharge from cervix. Cancer is correctly confirmed by testing estrogen, progesterone from white discharge from cervix or menstrual blood during menses in females.

\section{Characterization and Procedure for Diagnosing Cancer Using Biosensor}

Procedure for diagnosing cancer is by taking a little blood sample from the area where it is attacked. The biosensor is made ready for testing the blood sample. It is dipped in ferroferri solution and Cyclic Voltametry is performed. It leads to formation of oxidation and reduction cycles. The difference between the positive peak and negative peak is calculated. If the difference is $0.01 \mathrm{~V}$, then it is ready for testing. After this ferroferri test, the biosensor is tested for PANI (electro chemical polymerization of ANALINE).This is done by mixing HCL acid and Analine acid in appropriate ratios and poured into the biosensor cell. The 3 electrodes are Glassy Carbon for working electrode, Reference electrode is made of Agcl or Ag. The counter electrode is made of platinum [6].

After the CV of PANI is performed, the biosensor working electrode gets polymerized with analine and HCL. The test is performed with phosphate buffer solution $(\mathrm{Pb} 7)$.

Now Glucose Oxidase (GODx) is drop casted though micropipette into the bulk solution and this is tested for Cyclic voltammetry in Electro com software. Now the glassy carbon is polymerized and coated with GODx. After the above test, blood is mixed with bulk solution; the blood sample is referred to as ANALYTE. The analyte mixed bulk solution is tested for detection of cancer. Cancer cells with less amount of oxygen lead to low value of current. Whereas non cancer cells with high amount of oxygen lead to high current in redox cycle.

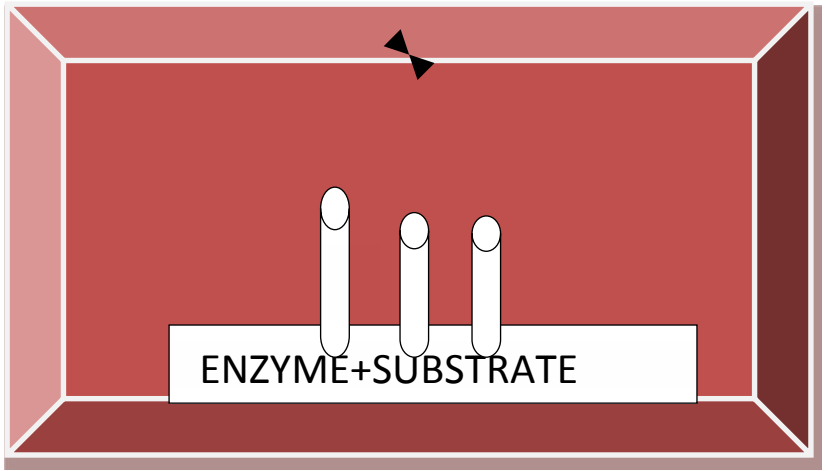

Figure 3: The above diagram represents the biosensor under QUASI STEADY STATE CONDITION with enzyme and substrate. 
Citation: Babu KK (2016) Modeling, Simulation of 3D Label Free Nano Amperometric Biosensor for Early Diagnosis of Cancerous Cells with Sustainable Interfacial Coefficients. J Biosens Bioelectron 7: 222. doi: 10.4172/2155-6210.1000222

Page 3 of 3

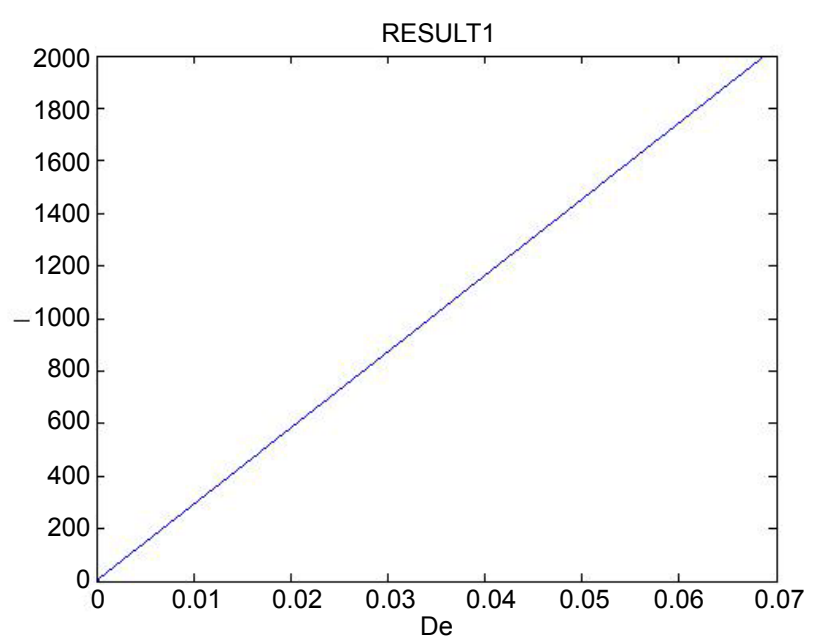

Figure 4: The above figure shows the variation of CURRENT vs De, which is increasing sharply for non cancerous cells. The result will be inverted in cancerous cells.

\section{Result}

\section{Interfacial coefficients}

Interfacial Coefficients=N.De.F.Q

By using the above equation a small program is written in MATLAB for Current versus De. The result is shown below (Figure 4).

\section{Nano technology}

Nano materials such as Nano wires and Graphene can be used in fabrication of device. Graphene made electrodes ors are used for their feasibility to biological environment with Good Young s modulus, Quality factor and Stress strain relationship.

\section{Analysis}

With this Biosensor, I could do Mathematical modeling and simulate it numerically. With the developed equations, we can fabricate the device for the purpose of early diagnosis of CANCER with the simulated outputs. This device can be used in Health Care and in Clinics in future to know the condition of healthy Bio molecules and Diseased Bio molecules.

\section{Conclusion}

In this paper I discussed the mathematical modeling, characterization and simulation of amperometric biosensor with interfacial coefficients in early Diagnosis of cancer.

\section{References}

1. Kilho E (2012) Simulations in nano biotechnology. CRC Press, London. pp: $1-51$.

2. Baronas R, Ivanauskas F, Kulys J (2010) Mathematical modeling of biosensors: an introduction for chemists and mathematicians. Springer Series on Chemical Sensors and Biosensors.

3. Kulys J (2006) Biosensor response at mixed enzyme kinetics and external diffusion limitation in case of substrate inhibition biosensors. Nonlinear Analysis: Modelling and Control 11: 385-392.

4. Teik-Cheng Lim (2010) Nanosensors: theory and applications in industry healthcare and defense. Biosensors - Health Care and Defense. CRC press, Taylor and Francis group, London. p: 334.

5. https://en.wikipedia.org/wiki/Literature_review

6. Supriyo D (2013) Nano applications of biosensors. 